\title{
Rehabilitation treatment of enteral nutrition whey protein in lung cancer patients in southern China
}

\author{
Meilin $\mathrm{ZHAO}^{1 *}$ (D), Qingqing $\mathrm{ZHAN}^{2}$
}

\begin{abstract}
The aim of this study is to observe the clinical efficacy of enteral nutrition support therapy in patients with lung cancer chemotherapy in southern China. 212 patients with lung cancer chemotherapy were divided into treatment group and control group, with 30 cases in each group. Patients in the two groups were treated with a normal diet, anti-infection, oxygen inhalation, antispasmodic and asthma, phlegm elimination, correction of acid-base imbalance, and electrolyte disturbance. Patients in the control group ate according to usual dietary habits, and infused intravenously with $20 \%$ fat milk $250 \mathrm{~mL}$. $8.5 \%$ compound amino acid $250 \mathrm{~mL}, 10 \%$ glucose injection $500 \mathrm{~mL}$ and vitamins and other general nutrition support treatment. Patients in the enteral nutrition treatment group were given oral nutritional support for Lishikang integrin-type nutritional solution based on the control group. Patients with hypoproteinemia were supplemented with an appropriate amount of whey protein powder for 2 weeks. Before and after treatment, nutritional assessment, biochemical index monitoring, and adverse reactions were observed in the two groups of patients. Compared with the control group, the enteral nutrition treatment group increased anthropometric values, improved lung function, and increased serum albumin. There was a significant difference between the two groups $(\mathrm{P}<0.05)$. Enteral nutrition support treatment can significantly improve the nutritional status of patients with lung cancer, we need improve the immune function of patients and tolerance to chemotherapy.
\end{abstract}

Keywords: lung cancer; chemotherapy; enteral nutrition support treatment.

Practical Application: Enteral nutrition support treatment can improve the nutritional status of patients with lung cancer.

\section{Introduction}

Lung cancer is one of the malignant tumors with a high incidence, and malnutrition is a global public health problem for the disease (Adie et al., 2020; Boldrin et al., 2019; Canale et al., 2019). According to statistics, the incidence of malnutrition in hospitalized patients with lung cancer is about 20-50\% (Andrews Wright \& Goss, 2019; Arroyo et al., 2019). At present, radical surgery can effectively remove the lesion, and it is still an effective method to treat early and middle lung cancer and prolong the survival time of patients (Lee et al., 2019; $\mathrm{Lu}$ et al., 2020; Shi et al., 2019). However, patients with lung cancer have poor nutrition status and weakened immune function before surgery (Park et al., 2020; Ulmann et al., 2019). At the same time, due to the stress response brought by surgery, malnutrition will be further exacerbated, which will affect the immune function of patients. Many patients with lung cancer due to chemotherapy-induced gastrointestinal adverse reactions and the disease itself often have varying degrees of malnutrition, and even cachexia, which seriously affects the treatment effect and prognosis of patients (Toda et al., 2020).

Because lung cancer is a malignant wasting disorder, patients with different degrees of nutritional disorders will develop as the disease progresses (Friedberg et al., 2019; Yuan et al., 2018; Zongwen et al., 2017). At the same time, as the patient's body function decreases with age, the lack of disease recovery capabilities makes it easy to increase malnutrition. This situation not only affects the physiological parameters of the patient, but also affects its prognosis. Therefore, in the nutritional treatment of patients with lung cancer chemotherapy, it is very important to try to reverse or prevent the continued development of malnutrition. Enteral nutrition is not only safe and inexpensive, but also meets the body's normal physiological needs and protects the intestinal mucosal barrier (Ye et al., 2019; Lyu et al., 2019; Chow et al., 2020; Han et al., 2018).

Malnutrition and weakened immune function will adversely affect lung cancer patients after surgery, and are important risk factors for recurrence and metastasis (Cheng et al., 2018; Lee et al., 2017; Gavazzi et al., 2016). Studies have shown that enteral nutrition support therapy is a commonly used treatment and has an important role in improving the body's resistance. Enteral nutrition support therapy is rationally applied, and it can effectively regulate the immune and metabolism regulation by providing nutritional substrates required for cell metabolism (Yang et al., 2018; Xie et al., 2018). This study applied enteral nutrition support to patients with lung cancer chemotherapy in southern China. The clinical effects and safety of the patients were observed and their effects on the nutritional status of patients were observed. 


\section{Materials and methods}

\subsection{General demographic information}

A total of 212 patients receiving chemotherapy for lung cancer were selected from a hospital in southern China from January 2017 to December 2018. Among them, 142 were males and 70 were females, aged 41 to $72(55.3 \pm 5.6)$ years old, and all were treated with chemotherapy after diagnosis of lung cancer. Lung cancer chemotherapy patients were divided into two groups, that is, the treatment group and the control group, with 106 cases in each group, and observed for 2 weeks. Patients in the two groups were matched according to sex, age, disease type, condition, nutritional status, and chemotherapy regimen. There was no significant difference between the two groups $(\mathrm{P}>0.05)$, and they were comparable. Exclusion criteria: those with a history of metabolic disease and inflammatory bowel disease. People with concurrent heart, liver, and kidney failure. Those with gastrointestinal stress ulcers and bleeding. There are those who apply blood products.

\subsection{Nutrition support methods}

Control group

Eat according to the patient's usual eating habits. Peripheral intravenous infusion of $250 \% 20 \%$ fat milk $250 \mathrm{~mL}, 8.5 \%$ compound amino acid $250 \mathrm{~mL}, 10 \%$ glucose injection $500 \mathrm{~mL}$, appropriate amount of vitamins and trace elements, and other general nutrition support treatment. $3284.4 \mathrm{~kJ}(785 \mathrm{kcal}) / \mathrm{d}$, nitrogen is $3.47 \mathrm{~g} / \mathrm{d}$.

\section{Treatment group}

On the basis of the control group, Lisikang (Xi'an Libang Clinical Nutrition Co., Ltd.) integrin-type nutritional solution was taken orally (The main ingredients include maltodextrin, casein, whey protein, soy protein isolate, corn oil, medium chain triacylglycerol, phospholipids, glucose, dietary fiber, glutamine, multivitamin, and multimineral), $200 \mathrm{~mL}$ (1 kcal/mL) 4 times a day. For patients with hypoproteinemia $(<27 \mathrm{~g} / \mathrm{L})$, enter an appropriate amount of whey protein powder in the intestine, 20-30 g per day, divided into two doses. Patients who cannot eat by mouth are given a nasogastric tube.

\subsection{Detection indicators and methods}

Before treatment and after 2 weeks of treatment, nutrition evaluation, biochemical index monitoring and clinical adverse reaction observation were performed on the two groups of patients.
Body nutrition evaluation includes weight $(\mathrm{kg})$, triceps brachial skin wrinkle thickness (TSP) to measure the sebum thickness at the midpoint of the line between the left shoulder peak and the ulna olecranon, and the middle arm circumference (MAMC). Laboratory tests: blood routine, serum total protein and albumin. Clinical observation indicators include: the occurrence of adverse reactions such as diarrhea, bloating, abdominal pain, intestinal cramps, nausea, vomiting, and constipation.

\subsection{Statistical methods}

Data were analyzed using SPSS 23.0 statistical software. Grade data were compared using the chi-square test. Measurement data are expressed as $\mathrm{x} \pm \mathrm{s}$. Group design uses t-test. Paired design uses paired t test. Bilateral $\mathrm{P} \leq 0.05$ was considered statistically significant.

\section{Results}

\subsection{Anthropometric value}

The weight gain of patients in the control group and the treatment group before and after treatment was $(0.52 \pm 0.21) \mathrm{kg}$ and $(2.16 \pm 0.75) \mathrm{kg}$, respectively, the difference was statistically significant $(t=21.727, \mathrm{P}<0.05)$. The triceps brachial skin wrinkle thickness (TSP) of the control group and the treatment group before and after treatment were $(0.31 \pm 0.19) \mathrm{mm}$ and $(2.13 \pm 0.27)$ $\mathrm{mm}$, respectively, and the difference was statistically significant ( $t=55.468, P<0.05)$. Patients in the control group and the treatment group before and after treatment had an increase in the middle arm muscle circumference (MAMC) by $(0.58 \pm 0.31)$ $\mathrm{mm}$ and $(2.59 \pm 0.33) \mathrm{mm}$, respectively. The difference was statistically significant $(t=45.551, P<0.05)$. The analysis results are shown in Table 1.

\subsection{Nutrition-related indicators}

The total protein of patients in the control group before and after treatment was $(42.01 \pm 1.18) \mathrm{g} / \mathrm{L}$ and $(46.14 \pm 1.67) \mathrm{g} / \mathrm{L}$, the difference was statistically significant $(P<0.05)$. The total protein before and after treatment in the treatment group was $(42.83 \pm 1.29) \mathrm{g} / \mathrm{L}$ and $(53.86 \pm 1.14) \mathrm{g} / \mathrm{L}$, and the difference was statistically significant $(P<0.05)$. The difference in total protein after treatment between the treatment group and the control group was also statistically significant $(P<0.05)$. The albumin in the control group before and after treatment was $(25.22 \pm 3.18)$ $\mathrm{g} / \mathrm{L}$ and $(28.47 \pm 3.43) \mathrm{g} / \mathrm{L}$, the difference was statistically significant $(P<0.05)$. Patients in the treatment group before and after treatment had albumin levels of $(24.09 \pm 4.64) \mathrm{g} / \mathrm{L}$ and $(32.43 \pm 4.32) \mathrm{g} / \mathrm{L}$, the differences were statistically significant

Table 1. Comparison of anthropometric values before and after treatment in two groups of patients.

\begin{tabular}{lcccc}
\hline & $n$ & Weight gain $(\mathrm{kg})$ & TSP $(\mathrm{mm})$ & MAMC $(\mathrm{mm})$ \\
\hline Control group & 106 & $0.52 \pm 0.21$ & $0.31 \pm 0.19$ & $0.58 \pm 0.31$ \\
Treatment group & 106 & $2.16 \pm 0.75$ & $2.13 \pm 0.27$ & $2.59 \pm 0.33$ \\
$t(t$ test $)$ & & 21.727 & 55.468 & 45.551 \\
$P$ (Probability) & & $<0.001$ & $<0.001$ & $<0.001$ \\
\hline
\end{tabular}


$(P<0.05)$. The difference in albumin after treatment between the treatment group and the control group was also statistically significant $(P<0.05)$. Patients in the control group before and after treatment had hemoglobin $(7.17 \pm 1.75) \mathrm{g} / \mathrm{L}$ and $(7.91 \pm 2.23)$ $\mathrm{g} / \mathrm{L}$, respectively, and the difference was statistically significant $(P<0.05)$. The hemoglobin before and after treatment in the treatment group was $(7.23 \pm 1.63) \mathrm{g} / \mathrm{L}$ and $(9.68 \pm 2.45) \mathrm{g} / \mathrm{L}$, the difference was statistically significant $(P<0.05)$. The difference in hemoglobin between the treatment group and the control group after treatment was also statistically significant $(P<0.05)$. The analysis results are shown in Table 2.

\subsection{Clinical observation indicators}

After treatment, patients in the control group and the treatment group had a decrease in white blood cell counts of $71.7 \%$ and $40.6 \%$, respectively. The proportion of patients in the control group and the treatment group after treatment was $73.6 \%$ and $92.5 \%$, respectively. The difference was statistically significant (Chi-square value $=13.384, \mathrm{P}<0.05)$. The incidences of adverse reactions after treatment in patients in the control group and the treatment group were $67.0 \%$ and $32.1 \%$, respectively, and the difference was statistically significant (Chi-square value = 25.832, $\mathrm{P}<0.05)$. Only a few patients in the treatment group had bloating and diarrhea, which improved after symptomatic treatment, and no serious complications occurred. The analysis results are shown in Table 3.

\section{Discussion}

Lung cancer is a common malignant tumor in clinical practice, which seriously threatens human health and safety (Mirtavoos-Mahyari et al., 2019; Luo \& Xu, 2019). Chemotherapy is a common treatment for lung cancer patients (Guo et al., 2019; Luo et al., 2018). In the case of hunger and malnutrition, these patients are repeatedly treated with chemotherapy and radiation. Due to malnutrition, plasma protein levels in patients are reduced, and the body's absorption, distribution, metabolism, and excretion of chemotherapeutic drugs are impaired, which significantly affects the hemodynamics of chemotherapeutic drugs (Yang et al., 2019; Wang et al., 2019; Tissot et al., 2019). As a result, patients' adverse reactions to chemotherapeutic drugs increase, the body's tolerance decreases, and the effect of antitumor treatment is affected. The effects of chemotherapeutics on the body are not limited to tumor cells, but can also affect normal tissue cells. Clinically, patients often experience nausea, vomiting, anorexia and diarrhea. Sometimes even blood in the stool can seriously affect the patient's food intake and absorption, leading to malnutrition.

Chemotherapy can also cause stomatitis, sore throat, inflammation of the gastrointestinal mucosa, and liver dysfunction, aggravating the degree of malnutrition (Miyata et al., 2017; Debeljak et al., 2018; Yu et al., 2017; Chao et al., 2017). Some patients therefore refuse treatment or are forced to terminate treatment. The method of dripping nutrient solution by the intravenous infusion set used in the past has limited effect and cannot effectively meet the nutrition needs of the patient's body. Enteral nutrition is a nutritional support means pumped into the enteral nutrition suspension through a nasal catheter (Chen et al., 2019; Wang et al., 2018). Nutrients directly enter the patient's intestine, conforming to the form of gastrointestinal movement, and will not increase the intestinal osmotic load. The patient's gastrointestinal burden is small and the adaptation is good, which is conducive to the slow and uniform absorption of various nutrients and reduces the stimulation of the digestive tract. In addition, because of the need to fast water before surgery, early enteral nutrition support can stimulate digestive tract gland secretion, promote gastrointestinal absorption and digestive function recovery, and help improve immune function.

The early rational application of enteral nutrition has the following advantages(Peng et al., 2016; Chen et al., 2014; Fujita et al., 2012): enteral nutrition is beneficial to promote the recovery of gastrointestinal function, prevent bacterial translocation, and reduce the occurrence of enteric infection. Intestinal nutrient solution is absorbed by the portal vein system

Table 2. Comparison of nutritional indexes between two groups of patients before and after treatment (g/L).

\begin{tabular}{|c|c|c|c|c|}
\hline \multirow{2}{*}{ Nutrition index } & \multicolumn{2}{|c|}{ Control group } & \multicolumn{2}{|c|}{ Treatment group } \\
\hline & Before treatment & After treatment & Before treatment & After treatment \\
\hline Total protein & $42.01 \pm 1.18$ & $46.14 \pm 1.67^{\#}$ & $42.83 \pm 1.29$ & $53.86 \pm 1.14^{\#, *}$ \\
\hline Albumin & $25.22 \pm 3.18$ & $28.47 \pm 3.43^{\#}$ & $24.09 \pm 4.64$ & $32.43 \pm 4.32^{\#, *}$ \\
\hline Hemoglobin & $7.17 \pm 1.75$ & $7.91 \pm 2.23^{\#}$ & $7.23 \pm 1.63$ & $9.68 \pm 2.45^{\#, *}$ \\
\hline
\end{tabular}

Compared with control group, ${ }^{\star} \mathrm{P}<0.05$; Compared with before treatment, ${ }^{,} \mathrm{P}<0.05$.

Table 3. Comparison of clinical observations after chemotherapy between two groups of patients.

\begin{tabular}{lcccc}
\hline \multicolumn{1}{c}{ Group } & $\mathrm{n}$ & Decrease in white blood cell count $(\%)$ & Chemotherapy compliance (\%) & Incidence of adverse reactions (\%) \\
\hline $\begin{array}{l}\text { Control group } \\
\begin{array}{l}\text { Treatment } \\
\text { group }\end{array}\end{array}$ & 106 & $76(71.7)$ & $78(73.6)$ & $71(67.0)$ \\
$\begin{array}{l}\chi 2(\text { Chi-square } \\
\text { value })\end{array}$ & 106 & $43(40.6)$ & $98(92.5)$ & $34(32.1)$ \\
$P($ Probability) & & 20.861 & 13.384 & 25.832 \\
\end{tabular}


and transported to the liver. It is an active absorption process, which is beneficial to regulating visceral protein synthesis and metabolism. Enteral nutrition does not increase visceral blood flow and cardiac output, and can reduce the energy consumed by metabolic nutrients. Clinical application is simple, easy, safe and economical. Chemotherapy drugs not only have therapeutic effects, but also have serious toxic side effects. Therefore, patients with lung cancer chemotherapy are more likely to have different degrees of gastrointestinal adverse reactions during treatment, such as nausea, vomiting, diarrhea, and anorexia. Patients with serious adverse reactions even have clinical manifestations of blood in the stool, which has a more serious impact on the patient's daily diet and is prone to malnutrition.

The choice of nutritional therapy for chemotherapy patients follows the principle of "use the intestine when it is functional and can be used safely", and enteral nutrition is preferred (Lee et al., 2017; Garofolo, 2012; Nogueira et al., 2020). Enteral nutrition is not only safe and inexpensive, but also meets the body's normal physiological needs and protects the intestinal mucosa. In the case of adverse reactions to chemotherapy in patients with lung cancer, enteral nutrition support treatment should be given as soon as the gastrointestinal tract is functional. Prior to chemotherapy, nutritional needs should be emphasized, and active nutritional supplementation can reduce complications, increase tolerance of antitumor therapy, and improve the effect of chemotherapy. For most lung cancer patients with malnutrition, nutrition intervention and treatment during chemotherapy has become an indispensable comprehensive treatment. Enteral nutrition can take a small number of meals, from low concentration to high concentration, from little to more to gradually adapt the patient, and then with pure whey protein powder (Lee et al., 2017; Trindade et al., 2019). It has a very good improvement effect on patients with hypoproteinemia. After 2 weeks of nutritional support treatment, the patient's mental state has improved significantly and chemotherapy compliance has improved.

In this study, the anthropometric values and nutritional indexes of patients in the treatment group were better than those in the control group, indicating that increasing nutritional support can significantly improve the tolerance of patients with lung cancer to adverse reactions to chemotherapy. In this study, nutritional assessment and comprehensive, balanced and reasonable enteral nutrition support treatment were performed for patients in the treatment group. The results of the study suggest that the improvement of patients' nutrition-related indicators is higher than that of the control group, indicating that increasing nutritional support can significantly improve the nutritional status of patients with lung cancer chemotherapy. Compared with the two groups, the rate of decrease in white blood cell count, chemotherapy compliance, and incidence of nausea and vomiting after chemotherapy were better in the treatment group than in the control group. It shows that enteral nutrition and nutritional support can reduce the incidence of adverse reactions in lung cancer patients and increase compliance with chemotherapy.

In this study, only a few patients experienced adverse reactions during the treatment of enteral nutrition, such as mild swelling and diarrhea, which were all relieved after treatment, and no serious complications occurred, suggesting that enteral nutrition is safe and feasible. With the development of medicine and the continuous improvement of clinical nutrition awareness, enteral nutrition treatment has become more and more important in the clinic and has become an important part of comprehensive clinical treatment. Enteral nutrition support therapy has the advantages of simplicity, safety, and economy. In the case of adverse reactions to chemotherapy in patients with lung cancer, enteral nutrition support treatment should be given as soon as the gastrointestinal tract is functional.

Enteral nutrition treatment is now more and more valued clinically and has become an important part of comprehensive clinical treatment. Enteral nutrition support therapy has the advantages of simplicity, safety, and economy. The application effect is more significant, the incidence of complications is lower, it is easier for patients to accept, the compliance is higher, and it has more promotion significance.

\section{References}

Adie, Y., Kats, D. J., Tlimat, A., Perzynski, A., Dalton, J., Gunzler, D., \& Tarabichi, Y. (2020). Neighborhood disadvantage and lung cancer incidence in ever-smokers at a safety-net healthcare system: a retrospective study. Chest, 157(4), 1021-1029. PMid:31862438.

Andrews Wright, N. M., \& Goss, G. D. (2019). Third-generation epidermal growth factor receptor tyrosine kinase inhibitors for the treatment of non-small cell lung cancer. Translational Lung Cancer Research, 8(Suppl. 3), S247-S264. http://dx.doi.org/10.21037/tlcr.2019.06.01. PMid:31857949.

Arroyo, M., Bautista, R., Larrosa, R., Cobo, M. A., \& Claros, M. G. (2019). Biomarker potential of repetitive-element transcriptome in lung cancer. PeerJ, 7, e8277. http://dx.doi.org/10.7717/peerj.8277. PMid:31875158.

Boldrin, E., Nardo, G., Zulato, E., Bonanno, L., Polo, V., Frega, S., Pavan, A., Indraccolo, S., \& Saggioro, D. (2019). Detection of Loss of Heterozygosity in cfDNA of Advanced EGFR- or KRAS-Mutated Non-Small-Cell Lung Cancer Patients. International Journal of MolecularSciences, 21(1), 66. http://dx.doi.org/10.3390/ijms21010066. PMid:31861832.

Canale, M., Pasini, L., Bronte, G., Delmonte, A., Cravero, P., Crino, L., \& Ulivi, P. (2019). Role of liquid biopsy in oncogene-addicted nonsmall cell lung cancer. Translational Lung Cancer Research, 8(Suppl. 3), S265-S279. http://dx.doi.org/10.21037/tlcr.2019.09.15. PMid:31857950.

Chao, P. C., Lin, C. F., \& Chuang, H. J. (2017). Parenteral nutrition combined with enteral feeding improves the outcome of cancer patients. Asia Pacific Journal of Clinical Nutrition, 26(6), 1032-1038. PMid:28917228.

Chen, W., Zhang, Z., Xiong, M., Meng, X., Dai, F., Fang, J., Wan, H., \& Wang, M. (2014). Early enteral nutrition after total gastrectomy for gastric cancer. Asia Pacific Journal of Clinical Nutrition, 23(4), 607-611. PMid:25516318.

Chen, X., Yang, K., Yang, J., \& Li, K. (2019). Meta-analysis of efficacy of sijunzi decoction combined with enteral nutrition for the treatment of gastric cancer. Nutrition and Cancer, 72(5), 723-733. PMid:31418281.

Cheng, Y., Zhang, J., Zhang, L., Wu, J., \& Zhan, Z. (2018). Enteral immunonutrition versus enteral nutrition for gastric cancer patients undergoing a total gastrectomy: a systematic review and metaanalysis. BMC Gastroenterology, 18(1), 11. http://dx.doi.org/10.1186/ s12876-018-0741-y. PMid:29338698. 
Chow, R., Bruera, E., Arends, J., Walsh, D., Strasser, F., Isenring, E., Del Fabbro, E. G., Molassiotis, A., Krishnan, M., Chiu, L., Chiu, N., Chan, S., Tang, T. Y., Lam, H., Lock, M., \& DeAngelis, C. (2020). Enteral and parenteral nutrition in cancer patients, a comparison of complication rates: an updated systematic review and (cumulative) meta-analysis. Supportive Care in Cancer, 28(3), 979-1010. http:// dx.doi.org/10.1007/s00520-019-05145-w. PMid:31813021.

Debeljak, Z., Dundovic, S., Badovinac, S., Mandic, S., Samarzija, M., Dmitrovic, B., Milos, M., Maricic, L., Seric, V., \& Buljanovic, V. (2018). Serum carbohydrate sulfotransferase 7 in lung cancer and non-malignant pulmonary inflammations. Clinical Chemistry and Laboratory Medicine, 56(8), 1328-1335. http://dx.doi.org/10.1515/ cclm-2017-1157. PMid:29648993.

Friedberg, J. S., Culligan, M. J., Tsao, A. S., Rusch, V., Sepesi, B., Pass, H. I., Bueno, R., Burt, B., Sugarbaker, D. J., de Perrot, M., Adjei, A. A., Adusumilli, P. S., Hirsch, F. R., Malik, S. M., \& Harpole, D. J. Jr. (2019). A proposed system toward standardizing surgical-based treatments for malignant pleural mesothelioma, from the joint National Cancer Institute-International Association for the Study of Lung Cancer-Mesothelioma Applied Research Foundation Taskforce. Journal of Thoracic Oncology, 14(8), 1343-1353. http:// dx.doi.org/10.1016/j.jtho.2019.04.029. PMid:31136816.

Fujita, T., Daiko, H., \& Nishimura, M. (2012). Early enteral nutrition reduces the rate of life-threatening complications after thoracic esophagectomy in patients with esophageal cancer. European Surgical Research, 48(2), 79-84. http://dx.doi.org/10.1159/000336574. PMid:22377820.

Garofolo, A. (2012). Enteral nutrition during bone marrow transplantation in patients with pediatric cancer: a prospective cohort study. Revista Paulista de Medicina, 130(3), 159-166. http://dx.doi.org/10.1590/ S1516-31802012000300005. PMid:22790548.

Gavazzi, C., Colatruglio, S., Valoriani, F., Mazzaferro, V., Sabbatini, A., Biffi, R., Mariani, L., \& Miceli, R. (2016). Impact of home enteral nutrition in malnourished patients with upper gastrointestinal cancer: a multicentre randomised clinical trial. European Journal of Cancer, 64, 107-112. http://dx.doi.org/10.1016/j.ejca.2016.05.032. PMid:27391922.

Guo, M., Wu, F., Hu, G., Chen, L., Xu, J., Xu, P., Wang, X., Li, Y., Liu, S., Zhang, S., Huang, Q., Fan, J., Lv, Z., Zhou, M., Duan, L., Liao, T., Yang, G., Tang, K., Liu, B., Liao, X., Tao, X., \& Jin, Y. (2019). Autologous tumor cell-derived microparticle-based targeted chemotherapy in lung cancer patients with malignant pleural effusion. Science Translational Medicine, 11(474), 11. PMid:30626714.

Han, H., Pan, M., Tao, Y., Liu, R., Huang, Z., Piccolo, K., Zhong, C., \& Liu, R. (2018). Early enteral nutrition is associated with faster post-esophagectomy recovery in Chinese esophageal cancer patients: a retrospective cohort study. Nutrition and Cancer, 70(2), 221-228. http://dx.doi.org/10.1080/01635581.2018.1412477. PMid:29313724.

Lee, A., Oliveira Filho, R. S., Cardenas, T. C., Ozorio, G. A., Gropp, J. P. L., \& Waitzberg, D. L. (2017). Quality control of enteral nutrition therapy in cancer patients at nutritional risk. Nutrición Hospitalaria, 34(2), 264-270. http://dx.doi.org/10.20960/nh.721. PMid:28421777.

Lee, S. Y., Walter, V., Zhu, J., Salzberg, A. C., Liu, D. J., \& Connor, J. R. (2019). Impact of HFE variants and sex in lung cancer. PLoS One, 14(12), e0226821. http://dx.doi.org/10.1371/journal.pone.0226821. PMid:31856248.

Lu, H., Zhang, H., Wei, Y., \& Chen, H. (2020). Ambient mass spectrometry for the molecular diagnosis of lung cancer. Analyst, 145(2), 313-320. http://dx.doi.org/10.1039/C9AN01365B. PMid:31872201.

Luo, J., \& Xu, X. (2019). Dietary fiber intake and the risk of bladder cancer in the Prostate, Lung, Colorectal and Ovarian (PLCO) cohort. Carcinogenesis, 41(4), 478-482. http://dx.doi.org/10.1093/carcin/ bgz187. PMid:31872237.
Luo, M., Luo, Y., Mao, N., Huang, G., Teng, C., Wang, H., Wu, J., Liao, X., \& Yang, J. (2018). Cancer-associated fibroblasts accelerate malignant progression of non-small cell lung cancer via connexin 43-formed unidirectional gap junctional intercellular communication. Cellular Physiology and Biochemistry, 51(1), 315-336. http://dx.doi. org/10.1159/000495232. PMid:30453281.

Lyu, J., Li, T., Xie, C., Li, J., Xing, L., Zhang, X., Shen, L., Zhao, K., Zhao, R., Yang, D., Li, X., Zhu, S., Sun, W., \& Shi, H. (2019). China Society for Nutritional Oncology. Enteral nutrition in esophageal cancer patients treated with radiotherapy: a Chinese expert consensus 2018. Future Oncology, 15(5), 517-531. http://dx.doi.org/10.2217/ fon-2018-0697. PMid:30457348.

Mirtavoos-Mahyari, H., Ghadami, M., Khosravi, A., Esfahani-Monfared, Z., Seifi, S., Motevaseli, E., Pourabdollah, M., \& Modarressi, M. (2019). Cell free tumoral DNA versus paraffin block epidermal growth factor receptor mutation detection in patients with nonsmall cell lung cancer. Asian Pacific Journal of Cancer Prevention, 20(12), 3591-3596. PMid:31870098.

Miyata, H., Yano, M., Yasuda, T., Yamasaki, M., Murakami, K., Makino, T., Nishiki, K., Sugimura, K., Motoori, M., Shiraishi, O., Mori, M., \& Doki, Y. (2017). Randomized study of the clinical effects of omega-3 fatty acid-containing enteral nutrition support during neoadjuvant chemotherapy on chemotherapy-related toxicity in patients with esophageal cancer. Nutrition (Burbank, Los Angeles County, Calif.), 33, 204-210. http://dx.doi.org/10.1016/j.nut.2016.07.004. PMid:27644137.

Nogueira, A. C., Oliveira, R. A., \& Steel, C. J. (2020). Protein enrichment of wheat flour doughs: empirical rheology using protein hydrolysates. Food Sci \& Technol, 40(Suppl. 1), 97-105. http://dx.doi.org/10.1590/ fst.06219.

Park, S., Ahn, H. J., Yang, M., Kim, J. A., Kim, J. K., \& Park, S. J. (2020). The prognostic nutritional index and postoperative complications after curative lung cancer resection: a retrospective cohort study. The The Journal of Thoracic and Cardiovascular Surgery, 160(1), 276-285. e1. http://dx.doi.org/10.1016/j.jtcvs.2019.10.105. PMid:31859072.

Peng, J., Cai, J., Niu, Z. X., \& Chen, L. Q. (2016). Early enteral nutrition compared with parenteral nutrition for esophageal cancer patients after esophagectomy: a meta-analysis. Diseases of the Esophagus, 29(4), 333-341. http://dx.doi.org/10.1111/dote.12337. PMid:25721689.

Shi, M., Zhan, C., Shi, J., \& Wang, Q. (2019). Prediction of overall survival of patients with completely resected non-small cell lung cancer: analyses of preoperative spirometry, preoperative blood tests, and other clinicopathological data. Cancer Management and Research, 11, 10487-10497. http://dx.doi.org/10.2147/CMAR. S232219. PMid:31853200.

Tissot, C., Gay, P., Brun, C., \& Froudarakis, M. E. (2019). Novel insights into the systemic treatment of lung cancer malignant pleural effusion. The Clinical Respiratory Journal, 13(3), 131-138. http:// dx.doi.org/10.1111/crj.13005. PMid:30737898.

Toda, K., Ueyama, M., Tanaka, S., Tsukayama, I., Mega, T., Konoike, Y., Tamenobu, A., Bastian, F., Akai, I., Ito, H., Kawakami, Y., Takahashi, Y., \& Suzuki-Yamamoto, T. (2020). Ellagitannins from Punica granatum leaves suppress microsomal prostaglandin E synthase-1 expression and induce lung cancer cells to undergo apoptosis. Bioscience, Biotechnology, and Biochemistry, 84(4), 757-763. http:// dx.doi.org/10.1080/09168451.2019.1706442. PMid:31868102.

Trindade, M. B., Soares, B. C. V., Scudino, H., Guimarães, J. T., Esmerino, E. A., Freitas, M. Q., Pimentel, T. C., Silva, M. C., Souza, S. L. Q., Almada, R. B., \& Cruz, A. G.. (2019). Cheese whey exploitation in Brazil: a questionnaire survey. Food Sci \& Technol, 39(3), 788-791. http://dx.doi.org/10.1590/fst.07419. 
Ulmann, G., Jouinot, A., Tlemsani, C., Curis, E., Kousignian, I., Neveux, N., Durand, J. P., Goldwasser, F., Cynober, L., \& De Bandt, J. P. (2019). Lean body mass and endocrine status but not age are determinants of resting energy expenditure in patients with non-small cell lung cancer. Annals of Nutrition \& Metabolism, 75(4), 223. http://dx.doi. org/10.1159/000504874. PMid:31865308.

Wang, J., Zhao, J., Zhang, Y., \& Liu, C. (2018). Early enteral nutrition and total parenteral nutrition on the nutritional status and blood glucose in patients with gastric cancer complicated with diabetes mellitus after radical gastrectomy. Experimental and Therapeutic Medicine, 16(1), 321-327. http://dx.doi.org/10.3892/etm.2018.6168. PMid:29896256.

Wang, W., Jiang, X., Zhang, Y., Song, Y., \& Song, Z. (2019). Intracavitary chemotherapy with epidermal growth factor receptor-tyrosine kinase inhibitor (EGFR-TKI) is not superior to TKI monotherapy in controlling malignant pleural effusion recurrence in EGFR-mutated lung cancer patients. Journal of Thoracic Disease, 11(9), 3712-3720. http://dx.doi.org/10.21037/jtd.2019.09.36. PMid:31656643.

Xie, H., Lu, Q., Wang, H., Zhu, X., \& Guan, Z. (2018). Effects of probiotics combined with enteral nutrition on immune function and inflammatory response in postoperative patients with gastric cancer. Journal of the Balkan Union of Oncology, 23(3), 678-683. PMid:30003737.

Yang, F., Wei, L., Huo, X., Ding, Y., Zhou, X., \& Liu, D. (2018). Effects of early postoperative enteral nutrition versus usual care on serum albumin, prealbumin, transferrin, time to first flatus and postoperative hospital stay for patients with colorectal cancer: a systematic review and meta-analysis. Contemporary Nurse, 54(6), 561-577. http://dx.doi. org/10.1080/10376178.2018.1513809. PMid:30176764.
Yang, X., Xiang, M., Geng, L., Wen, Y., \& Du, X. (2019). Anlotinib combined with S-1 in the third-line treatment of stage iv non-small cell lung cancer: study protocol for Phase II clinical trial. Asian Pacific journal of cancer prevention. APJCP, 20(12), 3849-3853. PMid:31870132.

Ye, Y., Xu, Y., Fu, Q., Shen, P., Chen, Y., Zheng, P., Song, L., Chen, Y., \& Wang, J. (2019). Enteral nutrition support does not improve PNI in radiotherapy patients with locally advanced esophageal cancer. Nutrition and Cancer, 71(2), 223-229. http://dx.doi.org/10 .1080/01635581.2018.1559939. PMid:30663378.

Yu, H. M., Tang, C. W., Feng, W. M., Chen, Q. Q., Xu, Y. Q., \& Bao, Y. (2017). Early enteral nutrition versus parenteral nutrition after resection of esophageal cancer: a retrospective analysis. Indian Journal of Surgery, 79(1), 13-18. http://dx.doi.org/10.1007/s12262015-1420-7. PMid:28331260.

Yuan, B., Zhang, R., Hu, J., Liu, Z., Yang, C., Zhang, T., \& Zhang, C. (2018). WDR1 promotes cell growth and migration and contributes to malignant phenotypes of non-small cell lung cancer through $\mathrm{ADF} /$ cofilin-mediated actin dynamics. International Journal of Biological Sciences, 14(9), 1067-1080. http://dx.doi.org/10.7150/ ijbs.23845. PMid:29989053.

Zongwen, S., Song, K., Cong, Z., Tian, F., \& Yan, Z. (2017). Evaluation of efficacy and safety for bevacizumab in treating malignant pleural effusions caused by lung cancer through intrapleural injection. Oncotarget, 8(69), 113318-113330. http://dx.doi.org/10.18632/ oncotarget.22966. PMid:29371913. 